\title{
The impact of a standardized incident reporting system in the perioperative setting: a single center experience on 2,563 'near-misses' and adverse events
}

Anita J Heideveld-Chevalking ${ }^{1 *}$, Hiske Calsbeek², Johan Damen ${ }^{3}$, Hein Gooszen ${ }^{1}$ and André P Wolff,3

\begin{abstract}
Background: The reduction of perioperative harm is a major priority of in-hospital health care and the reporting of incidents and their causes is an important source of information to improve perioperative patient safety. We explored the number, nature and causes of voluntarily reported perioperative incidents in order to highlight the areas where further efforts are required to improve patient safety.

Methods: Data from the Hospital Incident Management System (HIMS), entered in the period from July 2009 to July 2012, were analyzed in a Dutch university hospital. Employees in the perioperatve field filled out a semi-structured digital form of the reporting system. The risk classification of the reported adverse events and 'near misses' was based on the estimated patient consequences and the risk of recurrence, according to national guidelines. Predefined reported incident causes were categorized as human, organizational, technical and patient related.

Results: In total, 2,563 incidents (1,300 adverse events and 1,263 'near-miss' events) were reported during 67,360 operations. Reporters were anesthesia, operating room and recovery nurses (37\%), ward nurses (31\%), physicians (17\%), administrative personnel (5\%), others (6\%) and unmentioned (3\%). A total of 414 (16\%) adverse events had patient consequences (which affected $0,6 \%$ of all surgery patients), estimated as catastrophic in 2, very serious in 34, serious in 105, and marginally serious in 273 cases. Shortcomings in communication was the most frequent reported type of incidents. Non-compliance with Standard Operating Procedures (SOPs: instructions, regulations, protocols and guidelines) was reported with 877 (34\%) of incident reports. In total, 1,194 (27\%) voluntarily reported causes were SOP-related, mainly human-based (79\%) and partially organization-based (21\%). SOP-related incidents were not associated with more patient consequences than other voluntarily reported incidents. Furthermore 'mistake or forgotten' (15\%) and 'communication problems' (11\%) were frequently reported causes of incidents.
\end{abstract}

Conclusions: The analysis of voluntarily reported perioperative incidents identified an association between perioperative patient safety problems and human failure, such as SOP non-compliance, mistakes, forgetting, and shortcomings in communication. The data suggest that professionals themselves indicate that SOP compliance in combination with other human failures provide room for improvement.

Keywords: Hospital incident reporting, Guideline adherence, Patient safety, Perioperative care, Quality improvement

\footnotetext{
* Correspondence: Anita.Heideveld-Chevalking@radboudumc.nl

'Department of Operating Theatres, Radboud University Medical Center, Geert Grooteplein-Zuid 10, Internal postal code 738, 6525, GA, Nijmegen, The Netherlands

Full list of author information is available at the end of the article
} 


\section{Background}

Patient safety is a global public health issue receiving rapidly increasing attention. Patient safety is the (near) absence of (the chance of) avoidable harm inflicted on the patient through the actions and/or negligence of employees or through flaws in the healthcare system [1]. Numerous medical record studies have shown that unsafe care may result in adverse events (AEs) leading to harm in $3-17 \%$ of hospital patients [2]. An $\mathrm{AE}$ is "an unintended injury or complication resulting in prolonged length of hospital stay, disability at the time of discharge or death caused by health care management and not by the patients' underlying disease" [3]. A total of 51-77\% of AEs in hospitals are related to perioperative care [2]. A systematic review reveals that $14 \%$ of perioperative patients experience some form of AEs, that $38 \%$ of these AEs are preventable and that $4 \%$ of patients experiencing AEs have fatal outcomes [4]. Preventable AEs are the result of care that falls below current professional standards and the expected performance of practitioners or care systems $[1,2]$.

To improve patient safety and reduce adverse events, a national safety management system has been implemented in Dutch hospitals ('Veiligheidsmanagementsysteem = VMS') between 2008-2012. VMS focuses on the management of risks (the prevention of patient harm and its possible consequences) and is described in the Netherlands Technical Agreement' (NTA) [5]. The starting point for this NTA was the report "Here you'll work safely, or you won't work here" [6]. VMS consists of systems for risk identification, risk analysis, risk evaluation, incident reporting, incident analysis, and managing recommendations and improvement measures.

The operating department (including the clinical operating and recovery rooms) of the Radboud university medical center introduced the Hospital Incident Management System (HIMS) in July 2009. HIMS aimed at facilitating the voluntarily and confidentially reporting of perioperative incidents. After using HIMS for three years, we set out to analyze whether there are specific types or patterns of the reported information and to detect the areas where further efforts are required to improve perioperative patient safety. Specifically, we wished to investigate the number and characteristics of the voluntarily reported perioperative incidents. From the start of recording we noticed that Standard Operating Procedure (SOP) non-compliance was a prominent reported cause of incidents.

Since humans are fallible, systems must be designed to prevent humans from making errors $[7,8]$. Standardisation, the use of guidelines and protocols, is generally considered to improve perioperative safety. Preventable patient harm may be the result of guideline non-compliance but unfortunately there is hardly any literature about this problem in perioperative care. Dutch hospital record review studies suggest that at least $10-15 \%$ of AEs are directly or indirectly related to procedure non-compliance $[9,10]$. The compliance rate of the use of surgical safety checklists ranges from $12 \%$ to $100 \%$ (mean $75 \%$ ) [11]. French research revealed that alarms are frequently ignored by the operating theatre staff [12]. English anesthesiologists witnessed that $22 \%$ of incidents during anaesthesia are related to protocol violations [13].

There is an association between undesirable perioperative events and subsequent critical perioperative outcomes [14]. Recent studies reveal also that better guideline compliance is associated with better perioperative outcomes $[15,16]$. Therefore, adherence to guidelines is an important target for safety improvement programs. This study was designed to provide data on the number, nature and causes of voluntarily reported perioperative incidents.

\section{Methods}

This retrospective study is performed in the Radboud university medical center, which has 953 beds and 25 operating rooms (ORs). All data were obtained from HIMS, a database that is developed by the Patient Safety Company (http://www.patientsafety.com), licensed to the Radboud university medical center and used by the operating department since July 2009. The study period lasted from the $1^{\text {st }}$ of July 2009 to the $1^{\text {st }}$ of July 2012 . Incidents in HIMS are reported as a) 'adverse events', i.e. any unintended or unexpected event which could have led or did lead to harm of one or more patients receiving hospital care and b) 'near-miss events', i.e. events or circumstances that nearly occurred but were prevented (through luck or intervention) and did not lead to patient harm. [1] Harm is defined as any injury to the patient which leads to an extension or increase in the treatment, to temporary or permanent physical, psychological and/or social functional loss, or to death [5]. The worsening of a patient's condition as a result of the natural progression of an disease is not considered 'harm' [5].

At the introduction of HIMS, hospital wide appointments were made for reporting of incidents, based on the national agreements [5]. All employees, including professionals working in the perioperative process were encouraged to report incidents in order to prevent them from happening again. They were requested to fill out a semi-structured digital form of the reporting system. At least the following had to be reported: date, time and location of the incident, a brief description of the event and the circumstances, the type of incident and possible causes, the potential patient impact and the estimated risk of recurrence of that incident, and the measures that may prevent the incident from repeating. The predefined categorization of incident types is illustrated in Figure 1. In Tables 1 and 2 an explanation of the used terms is 


\section{Type of Incidents $(n=2,563)$}

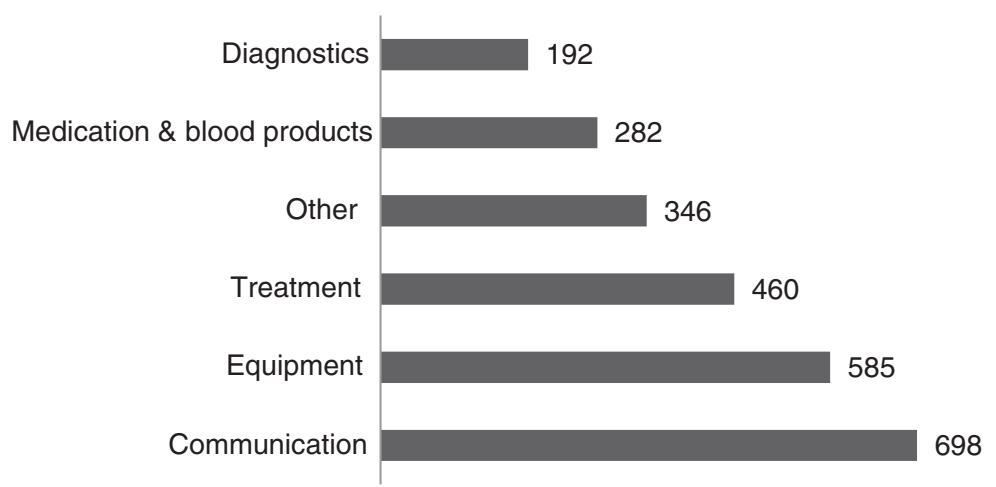

Figure 1 Predefined types of voluntarily reported perioperative incidents.

given, in particular of the concepts estimated risk of recurrence (Table 1) and estimated consequences for the patient (Table 2). This categorization of patient consequences is based on national guidelines as described in the NTA [5]. Based on the estimated patient consequences and risk of recurrence, the incident is automatically classified into four risk categories (Table 3). This risk classification is the basis for actions to be taken by the Operating Room Incident Reporting Committee (ORIRC) as described in Table 4. According to the Dutch consensus classification reported incident causes were classified as human, organizational, technical, patient related and other $[1,2]$.

The ORIRC consists of a surgeon, two anesthesiologists, a patient safety coordinator, a recovery room nurse, two operating room nurses, an anesthesia nurse, a logistic manager, a logistic employee, and a technician. The ORIRC reviews and discusses incidents weekly with priority to high risk events. Estimating the risk of recurrence and potential consequences for the patient at the time of reporting and before analysis of the incident may be difficult. Therefore, the ORIRC may adapt the risk score after analysis of the incident. Subsequently, the ORIRC undertakes actions, such as gathering additional information, cross-checking with the medical charts, and exploring key

Table 1 Explanation of risk of recurrence

\begin{tabular}{ll}
\hline Classification of the estimated risk of recurrence: \\
$\begin{array}{ll}\text { Almost inevitable } & \text { It will probably happen again within a few } \\
\text { hours or days }\end{array}$ \\
$\begin{array}{ll}\text { Probable } & \text { It will probably happen again within a week } \\
\text { Possible } & \text { It will probably happen again within a few weeks } \\
\text { Small } & \text { It will probably happen again within a few month } \\
\text { Very small } & \end{array}$ \\
\hline
\end{tabular}

The estimated risk of recurrence of the reported incidents. contributing factors through informal discussions with care providers, managers, and/or other expert(s), asking 'why' and 'what' influenced the occurrence of this (near)incident. Besides these analyzing actions, other activities of ORIRC are trend watching, advising to adjust products and procedures, providing feedback and spreading newsletters and safety alerts to all involved in perioperative care. After closing a report, all information is automatically anonymized. The information in HIMS is not used for blaming, shaming or (legal) actions against the reporting professional, but for improving the quality of patient care.

Descriptive statistics were used to describe the number, nature and causes of incidents. Chi-square tests with Yates' correction and odds ratios (ORs) with 95\% confidence limits (CL) were applied to test differences between physicians and non-physicians and between perioperative and hospital wide reporting behaviour. A p-value $<0.05$ is considered to show statistical significance.

Table 2 Explanation of patient consequences

\begin{tabular}{ll}
\hline Classification of patient consequences: \\
\hline Catastrophe & (Expected) death or (expected) severe permanent harm \\
Very serious & (Expected) permanent harm/major intervention like (re) \\
& operation and/or (expected) extended hospitalization \\
& or treatment $>7$ days/delay of treatment causing \\
& severe risk of harm \\
Serious & (Expected) temporary harm and/or severe pain, for \\
& which medical treatment is needed and/or (expected) \\
& extended hospitalization or treatment $>3$ days/delay \\
& of treatment causing risk of harm \\
Marginally & (Expected) minimal harm and/or pain, requiring minor \\
serious & treatment and/or (expected) extended hospitalization \\
& or treatment $<3$ days/delay of treatment causing \\
minimal risk of harm \\
None
\end{tabular}

The estimated potential patient consequences of the reported incidents. 
Table 3 Explanation of risk matrix

\begin{tabular}{llllll}
\hline $\begin{array}{l}\text { Patient } \\
\text { consequences }\end{array}$ & & & & & \\
Catastrophe & Extreme & Extreme & Extreme & Extreme & Extreme \\
Very serious & High & High & High & High & High \\
Serious & High & High & High & Medium & Medium \\
Marginally serious & High & High & Medium & Medium & Low \\
None & Medium & Medium & Medium & Low & Low \\
\hline Risk of & Almost & Probable & Possible & Small & Very small \\
recurrence & Inevitable & & & &
\end{tabular}

Risk matrix based on the estimated patient consequences and the estimated risk of recurrence of the incident.

\section{Results}

\section{Hospital-wide voluntarily reported incidents}

Hospital-wide key figures over the period July 2009-July 2012 are presented in Table 5. The occurrence of voluntarily reported incidents associated with procedure noncompliance within the operating department was not significantly different from hospital wide reporting of non-compliance with SOPs (34\% and 32,5\% respectively (OR 1.087; 95\% CL 0.998-1.184, $\mathrm{p}=0.084)$ ).

\section{Characteristics of the voluntarily reported perioperative incidents}

Perioperatively 2,563 incidents were voluntarily reported in HIMS: 1,300 adverse events and 1,263 'near-miss' events. The reporters were all professionals involved in perioperative patient care: anesthesia, operating room and recovery nurses (37\%), ward nurses (31\%), physicians (17\%), administrative personnel (5\%), and others (6\%). Of 85 (3\%) incidents the appointment of the reporter was not mentioned. Figure 1 provides an overview of the types of incidents; communication failures (27\%) and equipment failures (23\%) were the most frequently reported type of voluntarily reported perioperative incidents.

$\begin{aligned} & \text { Table } 4 \text { Explanation of reporting requirments based on } \\ & \text { the classified risk }\end{aligned}$
$\begin{array}{ll}\text { Extreme risk } & \begin{array}{l}\text { The reporter/ORIRC contacts the involved head of } \\ \text { incident } \\ \text { the department and checks whether the catastrophe } \\ \text { is handled according to the standard procedures, } \\ \text { meaning that the Board of Hospital Directors reports } \\ \text { the catastrophe to the Health Care Inspectorate. }\end{array} \\ \text { High risk incident } & \begin{array}{l}\text { The ORIRC gathers further information, analyzes } \\ \text { the incident, discusses the incident in a meeting, } \\ \text { formulates conclusions and/or improvement actions. }\end{array} \\ \text { Medium risk } & \begin{array}{l}\text { The ORIRC gathers further information, discusses } \\ \text { the incident in a meeting, formulates conclusions } \\ \text { incident }\end{array} \\ \text { and/or improvement actions. } \\ \text { Low risk incident }\end{array}$
$\begin{aligned} & \text { The ORIRC formulates conclusions and/or } \\ & \text { improvement actions. }\end{aligned}$

ORIRC = Operating Room Incident Reporting Committee. Reporting requirements based on the classified risk.
Table 5 Hospital-wide key figures, July 2009-July 2012

\begin{tabular}{|c|c|}
\hline Total number of admissions & 210,507 \\
\hline Total number of clinical operations & 67,360 \\
\hline Total number of voluntarily reported incidents: & 27,008 \\
\hline by physicians & 2,937 \\
\hline by non-physicians & 23,154 \\
\hline by reporters that did not mention their position & 917 \\
\hline \multicolumn{2}{|l|}{ Number of voluntarily reported incidents per type: } \\
\hline medication \& blood-related & 6,932 \\
\hline communication-related & 6,053 \\
\hline diagnostics-related & 4,183 \\
\hline treatment-related & 3,751 \\
\hline equipment-related & 2,421 \\
\hline other type-related & 3,668 \\
\hline $\begin{array}{l}\text { Total number of voluntarily reported causes } \\
\text { (median 1; range } 0-10 \text { causes per incident) }\end{array}$ & 48,055 \\
\hline \multicolumn{2}{|l|}{ Number of causes per category: } \\
\hline mistake/forgotten & 9,611 \\
\hline SOP not followed & 6,535 \\
\hline other & 31,909 \\
\hline Total number of SOP-related causes: & 10,543 \\
\hline SOP not followed & 6,535 \\
\hline SOP not known & 2,116 \\
\hline SOP not available, incomplete or unclear & 1,684 \\
\hline SOP not accessible & 208 \\
\hline Number of incidents with SOP cause & 8,789 \\
\hline
\end{tabular}

Patient consequences and risk of recurrence of reported perioperative incidents

HIMS characterized 1,822 (71\%) incidents as 'medium risk incidents' which is shown in Table 6. Table 7 presents a specification of the estimated patient consequences and risk of recurrence of incidents. Patient consequences were estimated to have been inflicted 414 (32\%) of 1,300 adverse events: 273 events were considered to have caused minimal patient harm and/or pain, 105 temporary patient harm and/or severe pain, and 34 permanent patient harm and/or needing major intervention

Table 6 Risk classification of the 2,563 voluntarily reported perioperative incidents

\begin{tabular}{lll}
\hline Risk & \multicolumn{2}{l}{ Total incidents } \\
\cline { 2 - 3 } & $\mathbf{n}$ & $\%$ \\
\hline Extreme risk & 3 & $(0.1 \%)$ \\
High risk & 349 & $(13.6 \%)$ \\
Medium risk & 1822 & $(71.1 \%)$ \\
Low risk & 389 & \\
Total & $\mathbf{2 5 6 3}$ & \\
\hline
\end{tabular}

Risk classification of the 2,563 voluntarily reported perioperative incidents. 
Table 7 Estimated patient consequences and risk of recurrence of the 1,300 voluntarily reported perioperative adverse events

\begin{tabular}{lllllll}
\hline Estimated patient consequences & & & & & Total \\
\hline Catastrophe & 0 & 0 & 0 & 1 & $\mathbf{2}$ \\
Very serious & 4 & 6 & 16 & 7 & 1 & $\mathbf{3 4}$ \\
Serious & 4 & 18 & 58 & 18 & $\mathbf{7}$ \\
Marginally serious & 22 & 47 & 146 & 44 & 14 & 51 \\
None & 134 & 228 & 335 & 138 & $\mathbf{2 7 3}$ \\
Total & $\mathbf{1 6 4}$ & $\mathbf{2 9 9}$ & $\mathbf{5 5 5}$ & $\mathbf{2 0 8}$ & $\mathbf{7 4}$ \\
Estimated risk of recurrence & Almost inevitable & Probable & Possible & Small & Negligible \\
\hline
\end{tabular}

Estimated patient consequences and risk of recurrence of the 1,300 voluntarily reported perioperative adverse events.

like (re)operation and/or extended hospitalization or treatment. Two catastrophic adverse events, with one mortality, were reported to both the hospital board and the Dutch Health Care Inspectorate. The risk of recurrence of the previously mentioned 414 adverse events was estimated as follows: possible recurrence within a day $(\mathrm{n}=30)$, within a week $(n=71)$, within a few weeks $(n=220)$, within a few months $(\mathrm{n}=70)$, and of 23 adverse events it was estimated that the event would occur not more frequently than once a year.

The estimated patient consequences and risk of recurrence of reported perioperative 'near-miss' events are presented in Table 8. In total 233 (18\%) of these 1263 'near-misses' were estimated as potentially harmful, which was classified as marginally serious in 107 near-incidents, serious in 81 , and very serious in 44 . One potential catastrophic 'near-miss' event concerned mechanical problems with a part of the operating table and is described as an example in Table 9.

A total of 2,149 (84\%) of the voluntarily reported perioperative incidents were considered to have caused no patient harm, or delay of treatment which caused no harm, as shown in the Tables 7 and 8 . The risk of recurrence in 381 of these 2,149 incidents were estimated to reoccur within a day, 505 within a week, 861 within a few weeks, 296 within a few months, and of 106 incidents it was estimated that the event would occur no more than once a year.

\section{Reported causes}

Table 10 shows the reported predefined causes of perioperative incidents and their classification. A total of 4,346 causes were reported (median 1, range $0-10$ per incident). In total 2,966 (68\%) incident causes were related to human factors, $1,004(23 \%)$ to organizational factors, $89(2 \%)$ to technical failure, 128 (3\%) were patient-related and 159 (4\%) were related to other factors. Most frequently reported causes were SOP not followed (16,2\%), human mistake or having forgotten $(15,4 \%)$ and communication problems $(11,5 \%)$. In total $1194(27,5 \%)$ SOP related causes were noted, as summarized in Table 10 part b.

\section{Reported causes of procedure non-compliance}

A more detailed analysis of the 1,194 SOP related causes showed that $79 \%$ was related to human failure: a SOP was known but not followed in 702 cases and not known in 245 cases. Organization related factors were: unavailable, inaccessible, incomplete and unclear SOPs in 247 (21\%) of cases. Procedure non-compliance was reported with 877 (34\%) of incidents; 648 SOP causes were reported with 471 adverse events, and 546 with 406 'nearmiss'events.

Table 11 summarize the patient consequences and risk of recurrence of SOP associated perioperative incidents. In 151 of the 877 SOP related incidents, the events were associated with patient harm, while 263 of 1,686 non

Table 8 Estimated potential patient consequences and risk of recurrence of the 1,263 voluntarily reported perioperative 'near-miss' events

\begin{tabular}{|c|c|c|c|c|c|c|}
\hline Patient consequences could have been & & & & & & Total \\
\hline Catastrophe & 0 & 0 & 1 & 0 & 0 & 1 \\
\hline Very serious & 10 & 7 & 15 & 6 & 6 & 44 \\
\hline Serious & 13 & 37 & 27 & 3 & 1 & 81 \\
\hline Marginally serious & 19 & 26 & 49 & 11 & 2 & 107 \\
\hline None & 205 & 207 & 434 & 138 & 46 & 1030 \\
\hline Total & 247 & 277 & 526 & 158 & 55 & 1263 \\
\hline Estimated risk of recurrence & Almost inevitable & Probable & Possible & Small & Negligible & \\
\hline
\end{tabular}

Estimated potential patient consequences and risk of recurrence of the 1,263 voluntarily reported perioperative 'near-miss' events. 
Table 9 Examples of reported perioperative incidents in HIMS

\begin{tabular}{|c|c|c|c|c|c|}
\hline \multicolumn{6}{|c|}{ Examples of reported perioperative incidents in HIMS } \\
\hline $\begin{array}{l}\text { HIMS risk } \\
\text { classification }\end{array}$ & Description & Event type & Incident type & $\begin{array}{l}\text { Function of } \\
\text { reporter }\end{array}$ & Reported cause \\
\hline Low risk & $\begin{array}{l}\text { Two patients did not have correct } \\
\text { marking signs although the surgeon had } \\
\text { signed the checklist. }\end{array}$ & Adverse event & Communication & $\begin{array}{l}\text { Recovery nurse at the } \\
\text { holding of the OR }\end{array}$ & SOP not followed \\
\hline \multirow[t]{3}{*}{ Medium risk } & $\begin{array}{l}\text { During surgery the following happened: } \\
\text { - } 30 \text { minutes waiting because the } \\
\text { patient arrived too late in the } O R \text {; }\end{array}$ & \multirow[t]{3}{*}{ Adverse event } & \multirow[t]{3}{*}{ Other } & \multirow[t]{3}{*}{ Anesthetic nurse } & $\begin{array}{l}\text { - Other organization-related } \\
\text { problem, namely: "delay } \\
\text { because of shortage of staff"; }\end{array}$ \\
\hline & $\begin{array}{l}\text { - For this operation there was no } \\
\text { blood typing performed; }\end{array}$ & & & & \multirow[t]{2}{*}{ - Human error or forgotten. } \\
\hline & $\begin{array}{l}\text { - During the time out it appeared that } \\
\text { the right size implant was not available. }\end{array}$ & & & & \\
\hline \multirow[t]{3}{*}{ High risk } & \multirow{3}{*}{$\begin{array}{l}\text { Surgery was performed without recent } \\
\text { available imaging. During surgery, it } \\
\text { appeared that metastases were increased } \\
\text { in size necessitating adjustment of } \\
\text { the surgical procedure. }\end{array}$} & \multirow[t]{3}{*}{ Adverse event } & \multirow[t]{3}{*}{ Diagnostics } & \multirow[t]{3}{*}{ Radiologist } & - SOP not known \\
\hline & & & & & $\begin{array}{l}\text { - SOP not available/ } \\
\text { incomplete/unclear }\end{array}$ \\
\hline & & & & & - Incorrect performance \\
\hline \multirow[t]{4}{*}{ Extreme risk } & \multirow{4}{*}{$\begin{array}{l}\text { The headrest of the surgical table suddenly } \\
\text { went loose, which could have caused the } \\
\text { head of the patient to bend downwards } \\
\text { uncontrollably but the head of the patient } \\
\text { was stabilized in time by the anesthesiologist. }\end{array}$} & \multirow{4}{*}{$\begin{array}{l}\text { 'Near-miss' } \\
\text { event }\end{array}$} & \multirow[t]{4}{*}{ Equipment } & \multirow[t]{4}{*}{ OR nurse } & - Broken material; \\
\hline & & & & & - Wrong design; \\
\hline & & & & & - Other human error, namely: \\
\hline & & & & & $\begin{array}{l}\text { "part of the table not } \\
\text { correctly fixated". }\end{array}$ \\
\hline
\end{tabular}

SOP related incidents were associated with patient harm (OR 1.13 (95\% CL 0.90-1.40), $\mathrm{p}=0.291$ ).

Most SOP related causes $(n=992)$ were reported by non-physicians, 170 by physicians and 32 by reporters who did not mention their function in the organization. Non-physicians reported less frequently SOP causes of incidents than physicians $(52 \%$ versus $68 \%, \mathrm{p}<0.0001)$, but non-physicians reported more often SOP causes of near-incidents $(48 \%$ versus $32 \%, \mathrm{p}<0.0001)$. There was no statistically significant difference between both groups in reporting human or organization related factors of SOP non-compliance. Both groups most frequently reported SOP causes with incidents that were classified as medium risk incidents.

To illustrate the characteristics of voluntarily reported perioperative incidents, examples are described in Table 9.

\section{Discussion}

We studied the characteristics of voluntarily reported perioperative incidents at our operating department in the period July 2009-July 2012. Reported incidents included 'near-miss' events as they can be seen as 'free lessons to be learned' [17]. Overall, 67,360 operations were performed in the three-year study period and 2,563 perioperative incidents were voluntarily reported. Most (84\%) of these incidents were not considered as potentially harmful for patients, but $16 \%$ were, which comprised $0.6 \%$ of all surgery patients. SOP non-compliance, shortcomings in communication, and mistakes or just 'having forgotten', appeared to be frequently reported incident causes. About one third of the reported perioperative incidents was associated with SOP non-compliance; $79 \%$ of these SOP-related causes were related to human failure. The SOP-related incidents were not associated with more patient consequences than other incidents. It is noteworthy that the percentage voluntarily reported incidents associated with SOP non-compliance within the operating department did not differ from the hospitalwide incidence.

There is increasing information that better guideline compliance is associated with improved perioperative outcomes $[15,16]$. A study on the implementation of a bundle of care to reduce postoperative surgical site infections showed that increased bundle compliance from $10 \%$ to $60 \%$ was associated with a significant $36 \%$ reduction in infection rate [16]. Another study in a Dutch university hospital on the effect of the use of a perioperative safety checklist showed a significant $56 \%$ reduction of the in-hospital 30-day mortality after surgery in patients with completed checklists whereas the mortality rate remained unchanged in patients with partially completed or noncompleted checklists [15]. The results of our study clearly show that a thorough analysis of the barriers that hinder adequate communication and compliance with SOPs is essential to further improve perioperative safety [18-20].

Incident reporting and investigation was first used in the 1940s to improve safety and performance of military aviation [21] and some decades later incident reporting 


\section{Table 10 Causes of perioperative 'near-misses' and adverse events}

\begin{tabular}{lll}
\hline A: Reported causes $(\mathbf{n}=\mathbf{4 , 3 4 6})$ of the perioperative incidents $(\mathbf{n}=\mathbf{2 , 5 6 3})$ \\
\hline HIMS predefined causes & $\mathbf{N}$ & $\mathbf{\%}$ \\
\hline Human & 702 & $16.2 \%$ \\
SOP not followed & 669 & $15.4 \%$ \\
Mistake/forgotten & 498 & $11.5 \%$ \\
Communication problem & 449 & $10.3 \%$ \\
Other human acting, namely ${ }^{*}$ & 245 & $5.6 \%$ \\
SOP not known & 161 & $3.7 \%$ \\
Professional not capable for task & 105 & $2.4 \%$ \\
Distracted & 77 & $1.8 \%$ \\
Unqualified or incorrect performance & 40 & $0.9 \%$ \\
Incorrect use & 20 & $0.5 \%$ \\
Wrong record filing & $\mathbf{2 , 9 6 6}$ & $\mathbf{6 8 . 2} \%$ \\
\hline Total human &
\end{tabular}

\begin{tabular}{|c|c|c|}
\hline \multicolumn{3}{|l|}{ Organizational } \\
\hline Other organizational, namely ${ }^{*}$ & 315 & $7.2 \%$ \\
\hline SOP not available, incomplete, or unclear & 217 & $5.0 \%$ \\
\hline Culture at workplace & 114 & $2.6 \%$ \\
\hline High workload & 115 & $2.6 \%$ \\
\hline Equipment/supply related, namely ${ }^{*}$ & 67 & $1.5 \%$ \\
\hline Inadequately trained professional & 67 & $1.5 \%$ \\
\hline Medical devices not available & 62 & $1.4 \%$ \\
\hline SOP not accessible & 30 & $0.7 \%$ \\
\hline Unclear instructions & 17 & $0.4 \%$ \\
\hline Total organizational & 1,004 & $23.1 \%$ \\
\hline \multicolumn{3}{|l|}{ Technical } \\
\hline Broken material & 61 & $1.4 \%$ \\
\hline Wrong design & 28 & $0.6 \%$ \\
\hline Total technical & 89 & $2.0 \%$ \\
\hline \multicolumn{3}{|l|}{ Patient-related } \\
\hline Other patient related, namely ${ }^{*}$ & 91 & $2.1 \%$ \\
\hline Patient condition & 19 & $0.4 \%$ \\
\hline Patient behaviour & 18 & $0.4 \%$ \\
\hline Total patient-related & 128 & $2.9 \%$ \\
\hline Other, namely*) & 159 & $3.7 \%$ \\
\hline Total & 4,346 & $100 \%$ \\
\hline \multicolumn{3}{|l|}{ B: Summary of SOP releated causes } \\
\hline SOP not followed & 702 & $16.2 \%$ \\
\hline SOP not known & 245 & $5.6 \%$ \\
\hline SOP not available, incomplete, or unclear & 217 & $5.0 \%$ \\
\hline SOP not accessible & 30 & $0.7 \%$ \\
\hline Total of SOP related causes & 1,194 & $27,5 \%$ \\
\hline
\end{tabular}

${ }^{*}$ Further described by the reporter in open text field. $\mathrm{SOP}=$ Standard Operative Procedure, including instructions, regulations, protocols, and guidelines. was introduced in anesthesiology [22]. Meanwhile, incident reporting has become a widely recommended method to gather information about AEs in hospital care [18] and several methods have been developed [13,23-25]. Much information about AEs in hospitals comes from the retrospective study of medical records [2,4,26,27]. However, retrospective record review has the well-known disadvantage that AEs may not have been identified or reported because they were not recorded in the medical file. These retrospective studies also rarely give information about 'near-miss'events. Patient's information is also a reliable source for the identification of care-related AEs [28]. Monitoring the performance of professionals by trained observers may provide the most reliable picture of perioperative practice $[13,29]$. However, these studies may underreport the actual rate of AEs because the researchers only observed during daytime of weekdays [29]. Smith at al. witnessed that around $20 \%$ of the incidents reported were the result of violation from existing protocols [13].

To further improve patient safety it is essential not only to get insight into the number, type, risk and causes of voluntarily reported incidents, but also to reach agreement on definitions and reproducible ways of reporting and scoring. The Netherlands Technical Agreement aims to contribute to the uniformity of the safety management system in hospitals and to create openness about patient safety towards patients and public. In order to improve the effectiveness of the national incident reporting system, we suggest further standardization of incident reporting data, specifically of the categorization of the types and causes of reported incidents. This has the potential to provide us with a system to compare hospital performance and to benchmark performance using a validated system.

The five basic elements essential for the successful translation from incident reporting to learning are 1) an open reporting culture allowing independent non-punitive data input, 2) the opportunity to freely narrate one's own version of the event, 3) an analysis that turns the incident report into a lesson, 4) adequate feedback [23], and 5) definitions clear enough to be used in other centres in order to be able to compare hospital performances. Investigating and analyzing incidents requires optimal engagement of physicians to get insight into the root cause and prevention of these events [23]. The use of a standardized framework for analysis of events has been recommended and introduced in several centers around the world including our center $[23,30]$. A positive safety culture is associated with increased willingness to report errors [31,32], with increased compliance with SOPs [33] and with fewer AEs [34]. Apparently professionals at our department felt safe enough to report communication failures and noncompliance with SOPs. They knew that the information will not be used to blame or undertake actions against the reporter and that after analysis of an incident the 
Table 11 Patient consequences and risk of recurrence of SOP related incidents

\begin{tabular}{|c|c|c|c|c|c|c|}
\hline \multicolumn{7}{|c|}{ A. Reported SOP-related perioperative adverse events and 'near-miss'events $(n=877)$} \\
\hline Estimated Patient consequences & & & & & & Total \\
\hline Catastrophe & 0 & 0 & 0 & 0 & 0 & 0 \\
\hline Very serious & 6 & 2 & 4 & 6 & 1 & 19 \\
\hline Serious & 6 & 12 & 39 & 4 & 0 & 61 \\
\hline Marginally serious & 15 & 27 & 79 & 17 & 4 & 142 \\
\hline None & 139 & 164 & 254 & 72 & 26 & 655 \\
\hline Total & 166 & 205 & 376 & 99 & 31 & 877 \\
\hline Estimated risk of recurrence & Almost inevitable & Probable & Possible & Small & Negligible & \\
\hline \multicolumn{7}{|c|}{ B. Reported SOP-related perioperative adverse events $(n=471)$} \\
\hline Catastrophe & 0 & 0 & 0 & 0 & 0 & 0 \\
\hline Very serious & 1 & 1 & 4 & 3 & 1 & 10 \\
\hline Serious & 2 & 9 & 25 & 3 & 0 & 39 \\
\hline Marginally serious & 8 & 16 & 62 & 13 & 3 & 102 \\
\hline None & 59 & 91 & 117 & 39 & 14 & 320 \\
\hline Total & 70 & 117 & 208 & 58 & 18 & 471 \\
\hline Estimated risk of recurrence & Almost inevitable & Probable & Possible & Small & Negligible & \\
\hline
\end{tabular}

information was anonymized to be used for training purposes and improving the quality of care, if deemed useful for this purpose.

A major weakness of incident reporting in all studies is under-reporting. Incident reporting may capture only $4 \%$ to $50 \%$ of AEs $[25,27,32-38]$. The reasons for not reporting are numerous: clinical factors (e.g. emergency scenario), time constraints, unfamiliarity with the system, problems with the definitions of what constitutes a reportable incident or near-incident, lack of a hospital policy of 'no disciplinary action' on incident reporting, lack of anonymity, lack of feedback and confusing aims of the reporting system as such $[13,18]$. However, the best policy to improve reporting behaviour is currently unknown [39]. Unfortunately, because of the risk of under-reporting, voluntary incident reporting is not a reliable instrument to monitor performance in e.g. the plan-do-study-act cycle. However, it may be used as qualitative monitor to identify areas that require further efforts to improve perioperative patient safety.

\section{Strength and limitations of the study}

We have used voluntarily reporting of incidents as an important source of information and hypothesized that this would make us capable to contribute to understanding and identifying clues for improving perioperative safety $[23,40]$. The present study highlights the areas where further efforts are required to improve patient safety. Because of the likelihood of under-reporting, our dataset cannot be considered a reproduction of all actually occurred incidents. A second point of attention is the fact that a substantial part of perioperative care is delivered outside the operating department. Therefore, our results, collected in the operating department, do not represent the full scope of perioperative incidents, as an unknown proportion will have been reported to other incident reporting committees within the hospital. Finally, this single center study may only reflect the culture and customs of our hospital. Since non-compliance with guidelines is a well-known phenomenon, our results are most likely not specific for our hospital. However, there is no information about the contribution of non-compliance with SOPs as cause of perioperative incidents in other hospitals.

\section{Conclusions}

Voluntarily incident reporting provide important and detailed information about perioperative patient safety problems. The most important finding of the present study is that professionals themselves report noncompliance with SOPs associated with human failure is an important area for improvement. Furthermore shortcomings in communication, mistakes, and forgetting were identified as important targets for improvement to reduce perioperative incidents in our hospital. This finding requires acknowledgement of the risk of human attitude, behaviour and failure. Moreover these findings challenge for the development of tools to improve guideline adherence and effective communication, in order to improve perioperative patient safety. 


\section{Competing interests}

The authors declare that they have no competing interests.

\section{Authors' contribution}

$\mathrm{AH}$ wrote the article and contributed substantially to the acquisition, analysis and interpretation of data. HC participated in drafting the article and contributed substantially to the interpretation of data. HG contributed substantially to the conception and design of the study, to the interpretation of data, and critically revised the article. AW contributed substantially to the conception and design of the study, to the analysis and interpretation of data, and critically revised the article. JD contributed substantially to the conception and design of the study, to the analysis and interpretation of data, and participated in drafting and critically revising the article. All authors approve this final version to be published. All authors agree to be accountable for all aspects of the work.

\section{Acknowledgements}

We are grateful for the advice and hospital data provided by Silvia van Gils, Process Improvement and Innovation Consultant, Radboud university medical center.

\section{Author details}

${ }^{1}$ Department of Operating Theatres, Radboud University Medical Center, Geert Grooteplein-Zuid 10, Internal postal code 738, 6525, GA, Nijmegen, The Netherlands. ${ }^{2}$ Department of IQ Healthcare, Radboud University Medical Center, Nijmegen, The Netherlands. ${ }^{3}$ Department of Anesthesiology, Radboud University Medical Center, Nijmegen, The Netherlands.

Received: 24 October 2014 Accepted: 27 November 2014 Published online: 10 December 2014

\section{References}

1. Wagner C, Van der Wal G: Voor een goed begrip, bevordering patiëntveiligheid vraagt om heldere definities. Medisch Contact 2005, 60:1888-1891.

2. Zegers $M$, de Bruijne $M C$, de Keizer $B$, Merten $H$, Groenewegen PP, van der Wal G, Wagner C: The incidence, root-causes, and outcomes of adverse events in surgical units: implication for potential prevention strategies. Patient Saf Surg 2011, 5:13

3. Brennan TA, Leape LL, Laird NM, Hebert L, Localio AR, Lawthers AG, Newhouse JP, Weiler PC, Hiatt HH: Incidence of adverse events and negligence in hospitalized patients. Results of the Harvard Medical Practice Study I. N Engl J Med 1991, 324:370-376.

4. Anderson $O$, Davis $R$, Hanna GB, Vincent $C A$ : Surgical adverse events: a systematic review. Am J Surg 2013, 206:253-262.

5. Netherlands Standardization Institute: NTA 8009:2011 Safety management system for hospitals and organizations which administer hospital care. Delft; 2011.

6. Willems R: Hier werk je veilig, of je werkt hier niet. Den Hague: Shell Netherlands; 2004

7. Kohn LT: CJM, Donaldson MS: To err is human, Building a Safer Health System. Washington, D.C.: National Acadamy Press; 1999.

8. Reason J: Human error: models and management. BMJ 2000, 320:768-770.

9. de Bruijne MC: ZM, Hoonhout LHF, Wagner C: Onbedoelde schade in Nederlandse ziekenhuizen, dossieronderzoek van ziekenhuisopnames in 2004. Amsterdam/Utrecht: EMGO/NIVEL; 2007.

10. LangelaanM BRJ, Broekens MA, Siemerink KM, Steeg L, van de Asscheman H, Bruijne MC, de Wagner C: Monitor Zorggerelateerde schade 2008, Dossieronderzoek in Nederlandse ziekenhuizen. NIVEL/EMGO+: Amsterdam/ Utrecht; 2010.

11. Borchard A, Schwappach DL, Barbir A, Bezzola P: A systematic review of the effectiveness, compliance, and critical factors for implementation of safety checklists in surgery. Ann Surg 2012, 256:925-933.

12. Amalberti $R$, Vincent $C$, Auroy $Y$, de Saint MG: Violations and migrations in health care: a framework for understanding and management. Qual Saf Health Care 2006, 15(Suppl 1):i66-i71.

13. Smith AF, Goodwin D, Mort M, Pope C: Adverse events in anaesthetic practice: qualitative study of definition, discussion and reporting. Br J Anaesth 2006, 96:715-721.
14. Boelle PY, Garnerin P, Sicard JF, Clergue F, Bonnet F: Voluntary reporting system in anaesthesia: is there a link between undesirable and critical events? Qual Health Care 2000, 9:203-209.

15. van Klei WA, Hoff RG, van Aarnhem EE, Simmermacher RK, Regli LP, Kappen TH, van Wolfswinkel L, Kalkman CJ, Buhre WF, Peelen LM: Effects of the introduction of the WHO "Surgical Safety Checklist" on in-hospital mortality: a cohort study. Ann Surg 2012, 255:44-49.

16. Crolla RM, van der Laan L, Veen EJ, Hendriks Y, van Schendel C, Kluytmans J: Reduction of surgical site infections after implementation of a bundle of care. PloS One 2012, 7:e44599.

17. Cooke $\mathrm{DL}$, Dunscombe PB, Lee RC: Using a survey of incident reporting and learning practices to improve organisational learning at a cancer care centre. Qual Saf Health Care 2007, 16:342-348.

18. Haller G, Courvoisier DS, Anderson H, Myles PS: Clinical factors associated with the non-utilization of an anaesthesia incident reporting system. Br J Anaesth 2011, 107:171-179.

19. Grol RWM, Eccles M, Davis D: Improving patient care. The implementation of change in health care. 2013:40-63

20. Fourcade $A$, Blache $J L$, Grenier $C$, Bourgain $J L$, Minvielle E: Barriers to staff adoption of a surgical safety checklist. BMJ Qual Saf 2012, 21:191-197.

21. Flanagan JC: The critical incident technique. Psychol Bull 1954, 51:327-358

22. Cooper JB, Newbower RS, Long CD, McPeek B: Preventable anesthesia mishaps: a study of human factors. Anesthesiology 1978, 49:399-406.

23. Mahajan RP: Critical incident reporting and learning. Br J Anaesth 2010, 105:69-75.

24. Barach P, Small SD: Reporting and preventing medical mishaps: lessons from non-medical near miss reporting systems. BMJ 2000, 320:759-763.

25. Anderson JE, Kodate N, Walters R, Dodds A: Can incident reporting improve safety? Healthcare practitioners' views of the effectiveness of incident reporting. Int J Qual Health Care 2013, 25:141-150.

26. Vincent C, Neale G, Woloshynowych M: Adverse events in British hospitals: preliminary retrospective record review. BMJ 2001, 322:517-519.

27. Gawande AA, Thomas EJ, Zinner MJ, Brennan TA: The incidence and nature of surgical adverse events in Colorado and Utah in 1992. Surgery 1999, 126:66-75.

28. Zhu J, Stuver SO, Epstein AM, Schneider EC, Weissman JS, Weingart SN: Can we rely on patients' reports of adverse events? Med Care 2011, 49:948-955.

29. Andrews LB, Stocking C, Krizek T, Gottlieb L, Krizek C, Vargish T, Siegler M: An alternative strategy for studying adverse events in medical care. Lancet 1997, 349:309-313.

30. Vincent C, Taylor-Adams S, Stanhope N: Framework for analysing risk and safety in clinical medicine. BMJ 1998, 316:1154-1157.

31. Naveh E, Katz-Navon T, Stern Z: Readiness to report medical treatment errors: the effects of safety procedures, safety information, and priority of safety. Med Care 2006, 44:117-123.

32. Frey B, Schwappach D: Critical incident monitoring in paediatric and adult critical care: from reporting to improved patient outcomes? Curr Opin Crit Care 2010, 16:649-653.

33. Aaa N: The impact of organizational climate on safety culture and individual behavior. Saf Sci 2000, 34:99-110

34. Mardon RE, Khanna K, Sorra J, Dyer N, Famolaro T: Exploring relationships between hospital patient safety culture and adverse events. J Patient Saf 2010, 6:226-232.

35. Lingard L, Espin S, Whyte S, Regehr G, Baker GR, Reznick R, Bohnen J, Orser B, Doran D, Grober E: Communication failures in the operating room: an observational classification of recurrent types and effects. Qual Saf Health Care 2004, 13:330-334.

36. Kingston MJ, Evans SM, Smith BJ, Berry JG: Attitudes of doctors and nurses towards incident reporting: a qualitative analysis. Med J Aust 2004, 181:36-39.

37. Noble DJ, Pronovost PJ: Underreporting of patient safety incidents reduces health care's ability to quantify and accurately measure harm reduction. J Patient Saf 2010, 6:247-250. 
38. Roehr B: US hospital incident reporting systems do not capture most adverse events. BMJ 2012, 344:e386.

39. Parmelli E, Flodgren G, Fraser SG, Williams N, Rubin G, Eccles MP: Interventions to increase clinical incident reporting in health care. Cochrane Database Syst Rev 2012, 8, CD005609.

40. Runciman WB, Merry A: A tragic death: a time to blame or a time to learn? Qual Saf Health Care 2003, 12:321-322.

Submit your next manuscript to BioMed Central and take full advantage of:

- Convenient online submission

- Thorough peer review

- No space constraints or color figure charges

- Immediate publication on acceptance

- Inclusion in PubMed, CAS, Scopus and Google Scholar

- Research which is freely available for redistribution 